\title{
Sarcoide equino na região Sul do Rio Grande do Sul: casuística de 20 anos
}

\author{
Equine sarcoid in the southern region of Rio Grande do Sul: 20-year casuistry \\ Sarcoide equino en la región sur de Rio Grande do Sul: casuística de 20 años
}

Recebido: 07/02/2022 | Revisado: 16/02/2022 | Aceito: 20/02/2022 | Publicado: 02/03/2022

Fabiano da Rosa Venancio

ORCID: https://orcid.org/0000-0002-4769-9360 Universidade Federal de Pelotas, Brasil

E-mail: fabianodarosavenancio@gmail.com

Taina dos Santos Alberti

ORCID: https://orcid.org/0000-0001-7568-8143 Universidade Federal de Pelotas, Brasil

E-mail: taina_alberti@yahoo.com

Lorena Alvariza Amaral

ORCID: https://orcid.org/0000-0003-4922-6740

Podiatria e Clinica Equina Albeitar Ltda, Brasil E-mail: lo1amaral@gmail.com

Rosimeri Zamboni

ORCID: https://orcid.org/0000-0003-0709-660X Universidade Federal de Pelotas, Brasil E-mail: rosi_zamboni@yahoo.com.br

Haide Valeska Scheid

ORCID: https://orcid.org/0000-0001-7855-6410 Universidade Federal de Pelotas, Brasil

E-mail: haidevaleskascheid@hotmail.com

Leonardo Clasen Ribeiro

ORCID: https://orcid.org/0000-0001-9031-8386

Universidade Federal de Pelotas, Brasil

E-mail: leonardo.clasen@gmail.com

Marcelo de Lima

ORCID: https://orcid.org/0000-0003-3102-1659 Universidade Federal de Pelotas, Brasil E-mail: mdelima.ufpel@gmail.com

Ana Lucia Schild

ORCID: https://orcid.org/0000-0003-2470-4785 Universidade Federal de Pelotas, Brasil

E-mail: alschild@terra.com.br

\begin{abstract}
Resumo
Os objetivos deste trabalho foram estudar a epidemiologia e a distribuição das lesões de sarcoide equino diagnosticado no Laboratório Regional de Diagnóstico da UFPel (LRD/UFPel) em um período de 20 anos, bem como determinar os principais tipos e, por meio da PCR, identificar o papilomavirus bovino (BPV) envolvido nas lesões. Os casos recebidos entre 2000 e 2020 foram resgatados dos protocolos de necropsia do laboratório. Os blocos parafinados de cada caso foram cortados em secções de $3-5 \mu \mathrm{m}$, corados por hematoxilina e eosina (HE) e reavaliados em microscópio ótico. As amostras encaminhadas ao laboratório em 2021 foram fixadas em formalina 10\% para histopatologia e imuno-histoquímica e parte, foi congelada e encaminhada ao Laboratório de Virologia e Imunologia da UFPel (LabVir/UFPel) para realização da PCR. No período foram diagnosticados 258 casos, dos quais 75,96\% na raça Crioula principalmente em equinos de dois a cinco anos $(42,64 \%)$. As características macroscópicas associadas à histopatologia permitiram determinar o tipo de sarcoide em cada caso. Em 46,8\% dos casos os sarcoides eram fibroblásticos. Dos 258 casos $61 \%$ eram únicos, observados principalmente nos membros e $32 \%$ eram múltiplos, presentes com mais frequência do tronco. O genoma dos BPVs não foi detectado pela PCR e a IHQ foi negativa para proteína S-100 e positiva para vimentina permitindo o diagnóstico diferencial de outras neoplasias cutâneas dos equinos. O registro de 258 casos de sarcoide em 20 anos permitiu estabelecer a sua epidemiologia na região Sul do Rio Grande do Sul e alerta para a importância da doença na região.
\end{abstract}

Palavras-chave: Histopatologia; IHQ; Neoplasia cutânea; Papilomavírus bovino; PCR; Sarcoide equino.

\section{Abstract}

The objective of this work was to study the epidemiology and distribution of equine sarcoid lesions diagnosed at the Laboratório Regional de Diagnóstico of UFPel (LRD/UFPel) over a period of 20 years, as well as to determine the main types and, the molecular identify of the bovine papillomavirus (BPV) associated to the lesions. Cases received 
between 2000 and 2020 were retrieved from the laboratory's necropsy protocols. The paraffin blocks of each case were cut into 3-5 $\mu \mathrm{m}$ sections, stained with hematoxylin and eosin (HE) and reassessed under an optical microscope. The samples sent to the laboratory in 2021 were fixed in $10 \%$ formalin for histopathology and immunohistochemistry and, an aliquot of frozen tissues were sent to the Laboratory of Virology and Immunology (LabVir/UFPel) for PCR. During the study period, 258 cases were diagnosed, of which $75.96 \%$ in the Crioula breed, mainly in horses aged two to five years $(42.64 \%)$. The macroscopic characteristics associated with the histopathology allowed us to determine the type of sarcoid in each case. In $46.8 \%$ of the cases, the sarcoids were fibroblastic. Of the 258 cases, $61 \%$ were single, mainly observed in the limbs, and $32 \%$ were multiple, most often present in the trunk. The BPV genome was not detected by PCR and the IHC was negative for protein S-100 and positive for vimentin, allowing the differential diagnosis of other equine cutaneous neoplasms. The record of 258 cases of equine sarcoid for approximately 20 years has contributed significantly to understand its epidemiology in southern Rio Grande do Sul and revealed the importance of the disease in the studied region.

Keywords: Histopathology; IHC; Skin neoplasm; Bovine papillomavirus; PCR; Equine sarcoid.

\begin{abstract}
Resumen
Los objetivos de este trabajo fueron estudiar la epidemiología y distribución de las lesiones de sarcoidosis equina diagnosticadas en el Laboratorio Regional de Diagnóstico de la UFPel (LRD/UFPel) en un período de 20 años, así como determinar los principales tipos y, mediante PCR, identificar el virus del papiloma bovino (BPV) implicado en las lesiones. Los casos recibidos entre 2000 y 2020 se recuperaron de los protocolos de necropsia del laboratorio. Los bloques de parafina de cada caso se cortaron en secciones de 3-5 $\mu \mathrm{m}$, se tiñeron con hematoxilina y eosina (HE) y se reevaluaron al microscopio óptico. Las muestras enviadas al laboratorio en 2021 fueron fijadas en formol al $10 \%$ para histopatología e inmunohistoquímica y parte fue congelada y enviada al Laboratorio de Virología e Inmunología de la UFPel (LabVir/UFPel) para PCR. En el período fueron diagnosticados 258 casos, de los cuales el 75,96\% en la raza Crioula, principalmente en equinos de dos a cinco años $(42,64 \%)$. Las características macroscópicas asociadas a la histopatología permitieron determinar el tipo de sarcoide en cada caso. En el 46,8\% de los casos las sarcoides eran fibroblásticas. De los 258 casos, el $61 \%$ fueron únicos, principalmente observados en las extremidades, y el $32 \%$ fueron múltiples, con mayor frecuencia presentes en el tronco. El genoma del BPV no fue detectado por PCR y la IHC fue negativa para proteína S-100 y positiva para vimentina, lo que permitió el diagnóstico diferencial de otras neoplasias cutáneas equinas. El registro de 258 casos de sarcoide en 20 años permitió establecer su epidemiología en la región sur de Rio Grande do Sul y alerta sobre la importancia de la enfermedad en la región.
\end{abstract}

Palabras clave: Histopatología; IHC; Neoplasia de piel; Virus del papiloma bovino; PCR; Sarcoide equino.

\title{
1. Introdução
}

O sarcoide equino é uma neoplasia cutânea localmente invasiva que não metastatiza e, às vezes, estende-se para as regiões mais profundas do subcutâneo e músculos adjacentes. Sarcoides são considerados tumores bifásicos, uma vez que se derivam da proliferação de dois componentes: os fibroblastos dérmicos e os queratinócitos epidérmicos (Funiciello \& Roccabianca, 2020). Sarcoide equino é a principal neoplasia que acomete a pele dos equídeos, apresentando-se como lesões únicas ou múltiplas com origem fibroblástica (Quinn, 2003; Gaynor et al., 2015, Abreu et al., 2018). Foi descrito pela primeira vez em 1936, tem uma distribuição mundial e pode afetar, também, outros equídeos, como burros, zebras e mulas, bem como outros mamíferos (Funiciello \& Roccabianca, 2020).

Este tumor caracteriza-se por intensa proliferação de fibroblastos arranjados em ninhos e feixes que se entrelaçam e assumem várias direções. As células neoplásicas são fusiformes ou estreladas com núcleos alongados, hipercromáticos e com atipia. Figuras de mitose são raras e há discreta neovascularização (Quinn, 2003; Brum et al., 2010; Souza et al., 2011; Assi sBrasil et al., 2015).

Na literatura são descritos seis tipos clínico patológicos de sarcoide equino, sendo eles: oculto, verrucoso, nodular, fibroblástico, misto e maligno (Lunardi et al., 2013; Knottenbelt, 2019; Semik-Gurgul, 2020). A patogenia e epidemiologia desta neoplasia ainda não estão bem determinadas, porém, sabe-se que há relação direta com o papiloma vírus bovino (BPV) 1, 2, UEL-4 e mais recentemente com o BPV 13 o qual foi, também, identificado em lesões de sarcoide (Anjos et al., 2010; Knottenbelt, 2019; Szczerba-Turek et al., 2019; Semik-Gurgul, 2020). Em 2020, o Comitê Internacional de Taxonomia Viral (ICTV) reorganizou a distribuição dos membros da família Papillomaviridae, agrupando os BPV-1, 2, 13 e 14 na mesma espécie, chamada de Deltapapillomavirus 4 (ICTV, 2021). 
Os BPVs, atuam por meio da ativação biológica do oncogêne E5, que é um dos principais oncopeptídeos que atuam na transformação das células normais do hospedeiro em células neoplásicas. Este oncogêne forma um complexo juntamente com o fator de crescimento derivado de plaquetas (PDGF-ß) e este complexo atua nos fibroblastos da pele, interferindo na mitogênese celular, o que contribui para a proliferação das células neoplásicas (Alcântara et al., 2015; Semik-Gurgul, 2020). O E5 atua, também, no complexo principal de histocompatibilidade (MHC-1) facilitando a evasão do sistema imunológico, permitindo assim que as células infectadas evitem a imunovigilância do hospedeiro, levando a transformação celular e proliferação tecidual, dando origem ao neoplasma (Semik-Gurgul, 2020).

O sarcoide equino ocorre em locais anatômicos mais suscetíveis a traumas recorrentes e de difícil cicatrização como: membros, cabeça, região periorbital, região ventral do abdômen, base da orelha, região axilar e inguinal. Além disso, sabe-se que não há predileção por sexo ou por raça, mas em algumas regiões acorre com maior frequência em animais castrados e em raças mais prevalentes na região estudada. A faixa etária mais afetada é entre dois e nove anos (Knottenbelt, 2019), sendo mencionada, também, a faixa etária entre três e seis anos (Semik-Gurgul, 2020) e, ainda, entre três e sete anos (Gomiero \& Tostes, 2015).

Os sinais clínicos são inespecíficos e normalmente estão associados com a localização dos tumores. O diagnóstico é baseado na história clínica, epidemiologia, características macroscópicas e histológicas das lesões. Para caracterizar e determinar a presença de agentes infecciosos como os BPVs, é necessário auxílio de técnicas moleculares como reação em cadeia da polimerase (PCR) para identificar o DNA e proteínas especificas destes agentes nas lesões.

Os objetivos deste trabalho foram estudar a epidemiologia e a distribuição das lesões de sarcoide equino recebidos no Laboratório Regional de Diagnóstico da Faculdade de Veterinária da Universidade Federal de Pelotas (LRD/UFPel) em um período 20 anos, determinando os principais tipos histológicos que ocorrem nos equinos da região de influência do laboratório, complementar o diagnóstico empregando a IHQ, bem como identificar o papilomavirus envolvido nas lesões pela técnica de biologia molecular PCR.

\section{Metodologia}

Foram resgatados dos protocolos de necropsia no banco de dados do LRD/UFPel, os casos de sarcoide equino recebidos no período de 2000 a 2020. Foram coletadas informações referentes a localização do sarcoide, número de lesões em um mesmo equino e tipo clínico de sarcoide. Além disso, foram coletadas informações referentes a idade, a raça e ao sexo dos animais afetados. Os equinos foram classificados como potros (até 24 meses), adulto jovem (25 a 60 meses), adulto (61 meses a 10 anos) e idosos aqueles com mais de 10 anos. Em nenhum dos casos o diagnóstico atribuído pelo patologista que recebeu o material foi modificado.

Os blocos parafinados de cada um dos casos de sarcoide foram cortados em secções de 3-5 $\mu$ m de espessura, corados pela técnica de hematoxilina e eosina (HE) e posteriormente reavaliados em microscópio ótico. Foram avaliadas em cada tumor as características histológicas como: hiperqueratose, hiperplasia da epiderme, arranjo celular, ulceração e/ou crosta e infiltrado inflamatório. Esses achados associados as características macroscópicas permitiram determinar o tipo de sarcoide diagnosticado.

As amostras de sarcoides encaminhadas ao LRD/UFPel durante o ano 2021 (sete casos) foram divididas sendo uma parte mantida em congelamento e outra parte fixada em formalina 10\% tamponada e processada rotineiramente para avaliação histológica. Os fragmentos congelados foram encaminhados ao Laboratório de Virologia e Imunologia da Faculdade de Veterinária da Universidade Federal de Pelotas (LabVir/UFPel), para identificar a presença de BPVs 1, 2, UEL-4 ou 13, através da técnica molecular de PCR. Em seis destes sete casos os tumores variavam de $2 \mathrm{~cm}$ a $7,5 \mathrm{~cm}$ de diâmetro e foram excisados completamente e a pele suturada, não ocorrendo recidiva em cinco deles até sete meses de acompanhamento. O 
sexto caso era um sarcoide recidivante. Não havia informações sobre o diâmetro e sobre a evolução do sétimo caso submetido a PCR.

Os sarcoides que foram submetidos a PCR para a deteç̧ão do BPV foram também selecionados para a realização da técnica de imuno-histoquímica, utilizado os anticorpos Vimentina para tecido mesenquimal e S100 para diferenciação de tumores de nervos e melanomas. Foram preparadas lâminas positivadas (Dako, Flex, IHC Microscopic Slides) com cortes histológicos de $3 \mu \mathrm{m}$, desparafinizadas e reidratadas em baterias de xilol e álcool. Para o bloqueio da peroxidase endógena foi adicionado peróxido de hidrogênio $10 \%$, diluído em metanol por 20 minutos em temperatura ambiente. Foi realizada a recuperação antigênica por 40 minutos a $96^{\circ} \mathrm{C}$ (Dako Target Retrieval Solution Low pH). Foram adicionados os anticorpos primários nas diluições, S100P (ACI 3010 A, B 1:200), Vimentina (V9 1:200), ambos Biocare Medical. As lâminas foram incubadas em câmara úmida por 18 horas (overnight) a $4^{\circ} \mathrm{C}$. Posteriormente foram incubadas com anticorpo secundário (gotas amarelas) e estreptavidina-peroxidase (gotas vermelhas) (Biocare Medical - kit MACH 4 Universal HPR-Polymer Detection System) por 20 minutos cada etapa, em seguida foi utilizado cromógeno para a revelação (3-amino-9-etilcarbazol AEC, K3469, DakoCytomation) (Tura et al., 2021).

As lâminas foram coradas com Hematoxilina de Harris (Procito), lavadas com água destilada e desidratadas em graduações crescentes de álcool, clarificadas em xilol e montadas com Entellan. Para o controle negativo foi utilizado PBS no lugar do anticorpo primário e como controle positivo foram utilizados fragmentos de intestino delgado. As lâminas foram avaliadas em microscópio óptico e classificadas como positivas ou negativas (Tura et al., 2021).

\subsection{Técnica de PCR}

\subsubsection{Extração de DNA}

Foi preparada uma suspensão a partir da maceração de 100mg das amostras de tecidos em $1000 \mu \mathrm{L}$ de TE buffer (10 mM Tris-Hcl pH.8.0, 0.1 M EDTA pH 8.0) adicionado a 100 $\mu \mathrm{L}$ de SDS (10\%) e $3 \mu \mathrm{L}$ de RNAse $(20 \mu \mathrm{g} / \mathrm{mL})$, sendo incubados por 30 minutos em banho-maria $\left(37^{\circ} \mathrm{C}\right)$. Logo após, foram adicionados $100 \mathrm{uL}$ de Proteinase $\mathrm{K}(20 \mu \mathrm{g} / \mathrm{mL})$ e realizada a incubação desse material por 3 horas a $56^{\circ} \mathrm{C}$ ou até a total digestão do tecido. O DNA foi extraído em solução de fenol, clorofórmio e álcool isoamílico (25:24:1), com precipitação overnight a $-20^{\circ} \mathrm{C}$ em etanol absoluto, ressuspendidos em água ultrapura e quantificados com QUbit (Invitrogen, Eugene, EUA) conforme recomendações do fabricante.

O DNA extraído foi submetido a reação em cadeia da polimerase (PCR), tendo como alvo parte do gene L1 do BPV, utilizando o par de primers FAP59/FAP64 (Forslund, 1999). As sequências dos primers, bem como o tamanho esperado do amplicon, podem ser visualizados na Tabela 1. A reação de PCR foi realizada em volume final de $25 \mu \mathrm{L}$, contendo uma

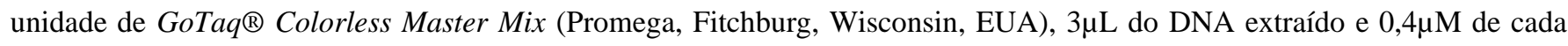
primer. Uma amostra de tecido positiva para Papillomavirus bovino foi utilizada como controle da extração, enquanto DNA viral previamente extraído foi utilizado como controle positivo para a PCR. Ambos controles positivos utilizados foram gentilmente cedidos pelo Dr Claudio Wageck Canal, UFRGS, RS. A amplificação foi realizada em termociclador nas condições $94^{\circ} \mathrm{C}$ por $5 \mathrm{~min}, 40$ ciclos de $94^{\circ} \mathrm{C}, 50^{\circ} \mathrm{C}$ e $72^{\circ} \mathrm{C}$ por $1 \mathrm{~min}$, com uma extensão final de $72^{\circ} \mathrm{C}$ por 7 min. Os produtos de PCR amplificados foram separados por eletroforese em gel de agarose a 1,5\%, corados com Brometo de Etídio $(0,5 \mathrm{mg} / \mathrm{mL})$ e visualizados em transiluminador UV após a eletroforese (100V, 60min) (Alcântara et al., 2015). 
Tabela 1 - Sequência dos primers e tamanho esperado do amplicon da Reação em Cadeia da Polimerase (PCR).

\begin{tabular}{lll}
\hline Primer & Sequência & Amplicon $(\mathbf{p b})$ \\
\hline FAP59 & 5'TAACWGTIGGICAYCCWTATT3’ & 480 \\
FAP64 & 5'CCWATATCWVHCATITCICCATC3’ & \\
\hline
\end{tabular}

Fonte: Autores.

\section{Resultados}

\subsection{Epidemiologia e patologia}

No período estudado foram recebidos no LRD/UFPel 2.331 materiais da espécie equina, dos quais 615 (26,38\%), eram referentes a lesões que envolviam a pele desta espécie animal. Dos 615 materiais, 258 (41,95\%) foram diagnosticados como sarcoide equino. Destes 258 casos 196 (75,96\%) eram equinos da raça Crioula, 54 (20,93\%) eram sem raça definida, 3 $(1,17 \%)$ eram Quarto de Milha e 2 casos $(0,77 \%)$ eram da raça PSI. Um caso de sarcoide $(0,39 \%)$ foi diagnosticado na raça Percheron, um na raça Apaloosa e um na Árabe. Com relação ao sexo dos equinos afetados 140 (54,26\%) ocorreram em fêmeas, 111 (43,02\%) em machos e em 7 casos $(2,72 \%)$ o sexo não estava informado no protocolo. Sarcoide afetou 17 potros (6,59\%), 110 equinos adultos jovens (42,64\%), 86 equinos adultos (33,33\%), e 25 equinos idosos $(9,69 \%)$. Em 20 casos $(7,75 \%)$ não havia informação sobre a idade dos equinos afetados.

Dentre os 258 diagnósticos de sarcoide, foram localizados 231 blocos de parafina para a caracterização histológica. Com base no padrão macroscópico e histológico 108 (46,8\%) eram do tipo fibroblástico (Figura 1A), 65 (28,1\%) eram do tipo misto (Figura 2A e B), 46 (19,9\%) do tipo verrucoso, 10 (4,3\%) eram do tipo oculto e dois $(0,9 \%)$ do tipo nodular. Dos 258 sarcoides diagnosticados 157 casos (61\%) eram únicos e em 83 (32\%) as lesões eram múltiplas. Em 18 casos (7\%) não havia esta informação nos protocolos. O número de sarcoides de acordo com o tipo, considerando a característica único ou múltiplo é apresentado na Tabela 2.

Figura 1 - 1A- Sarcoide tipo fibroblástico na porção distal do membro anterior direito de um equino. Observam-se áreas nodulares de alopecia e ulceração. 1B- Aspecto histológico do sarcoide fibroblástico. Observa-se área ulcerada à direita, hiperplasia do epitélio que se projeta para a derme onde há severa proliferação fibroblástica. [HE; obj.10x].
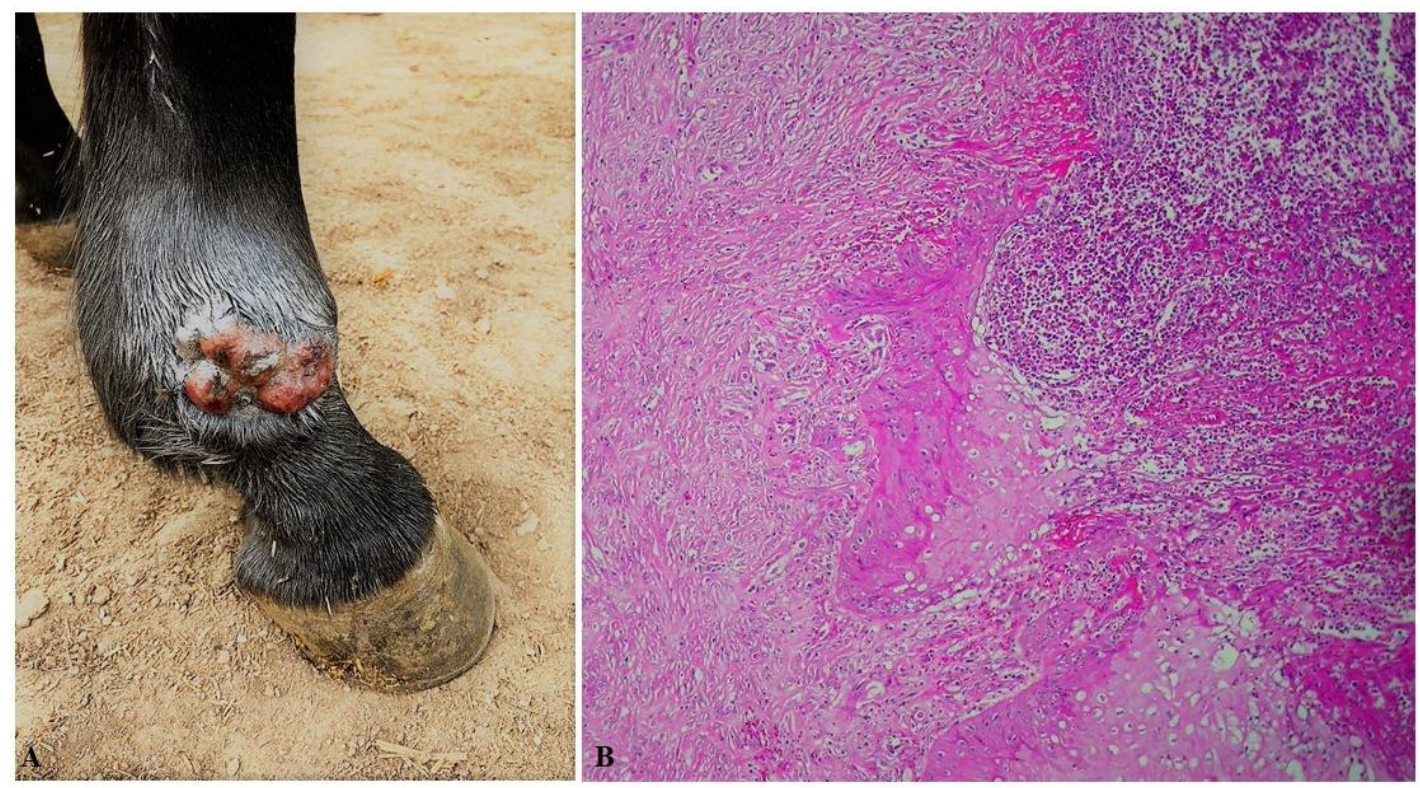

Fonte. Autores. 
Figura 2 - 2A- Sarcoide tipo misto na região demento e no peito e tecido proliferado de aspecto nodular e alopécico de um equino. Observam-se áreas nodulares com alopecia e ulceração. 2B-Aspecto histológico do sarcoide misto. Observa-se hiperplasia do epitélio (rete pegs) que se projeta para a derme formando ilhas de fibroblastos neoplásicos proliferados. [HE; obj.10x].
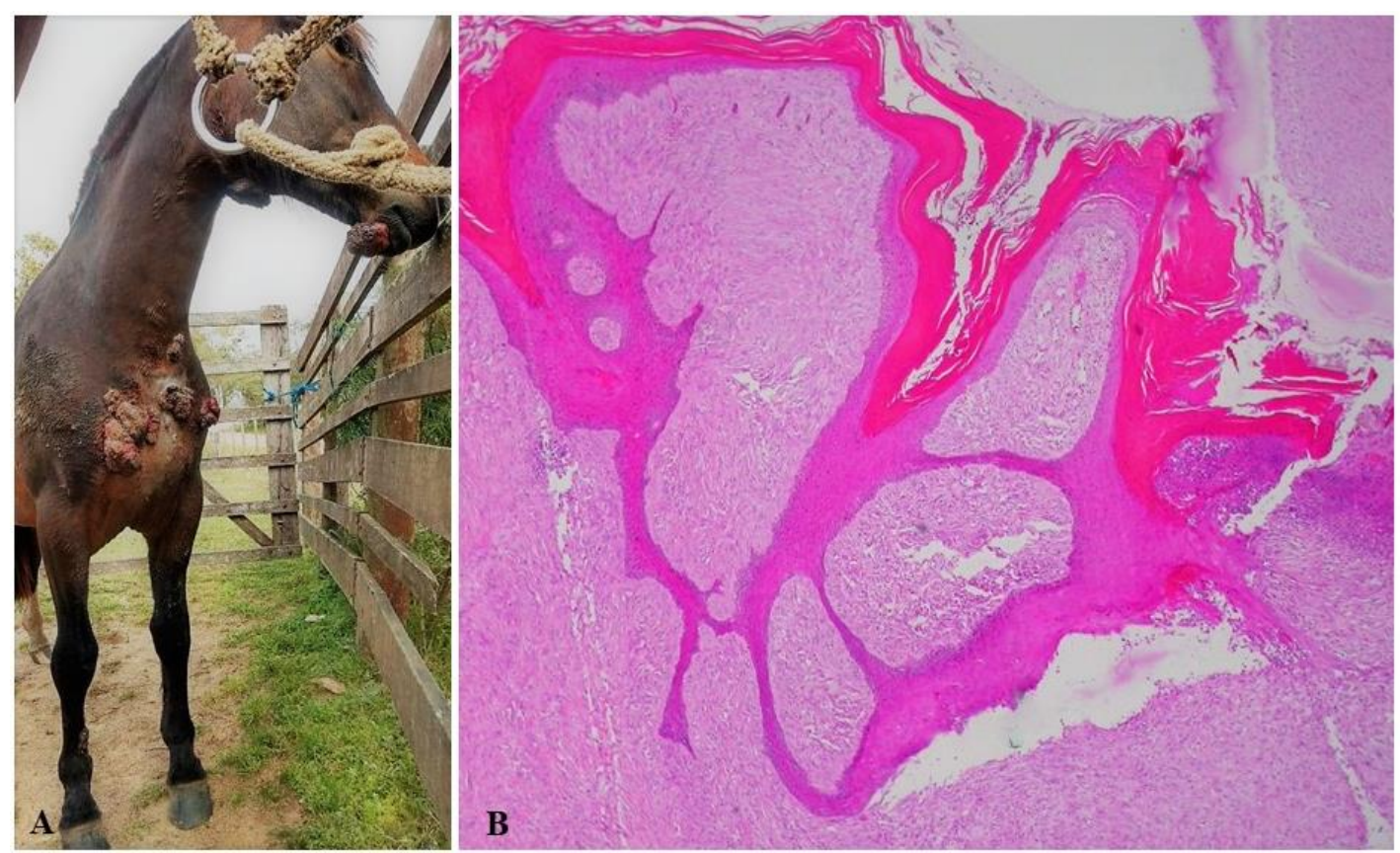

Fonte. Autores.

Tabela 2 - Número de cada tipo de sarcoide de acordo com a característica múltiplo ou único.

\begin{tabular}{lllllll}
\hline Característica & \multicolumn{2}{l}{ Tipo de sarcoide } & & & \\
\cline { 2 - 7 } & Fibroblástico & Misto & Verrucoso & Nodular & Oculto & Total \\
\hline Múltiplo & 35 & 18 & 16 & 0 & 3 & 72 \\
Único & 67 & 40 & 27 & 2 & 7 & 143 \\
NI & 6 & 7 & 3 & & 16 \\
\hline
\end{tabular}

Fonte. Autores.

O maior número de sarcoides únicos foi encontrado nos membros, independentemente do tipo, enquanto que os tumores múltiplos foram observados preferentemente no tronco com lesões presentes também na cabeça e nos membros. O tipo nodular foi observado somente na apresentação única, um em membro e o outro na cabeça.

Em 76 casos de sarcoide único a evolução do tumor estava disponível no protocolo e foi variável de um a três meses em 45 casos. Nos demais casos houve variação observando-se 13 casos com evolução de quatro a seis meses. Em 18 casos a evolução foi acima de sete meses. A evolução dos sarcoides múltiplos foi resgatada em 23 protocolos, no entanto este dado refere-se apenas ao tumor encaminhado ao laboratório. Em 10 casos a evolução variou de um a três meses, em cinco casos variou de quatro a seis meses e em oito casos foi acima de sete meses.

Nos sete casos de sarcoides recebidos durante o ano 2021, que foram submetidos a PCR, os equinos foram acompanhados após a excisão cirúrgica da lesão por um período de sete meses e não houve recidivas em nenhum dos animais. Nestes casos os tumores mediam de $2,0 \mathrm{~cm}$ a $7,5 \mathrm{~cm}$ de acordo com o veterinário remetente. Nos demais casos não foi possível obter esta informação. 


\subsection{Extração do DNA e Imuno-histoquímica}

Nas amostras de tecido analisadas, não foi detectada amplificação do BPV pela PCR utilizando os primers degenerados FAP59/64 que possuem como alvo regiões relativamente conservadas do gene L1 (Figura 3). A imunohistoquímica foi positiva para vimentina (Figura 4A), e negativa para proteína S-100 (Figura 4B).

Figura 3 - Gel de Eletroforese. C+ Controle positivo; CE+ Controle positivo da extração; A1-A7; Amostras 1 até 7 e CControle negativo.

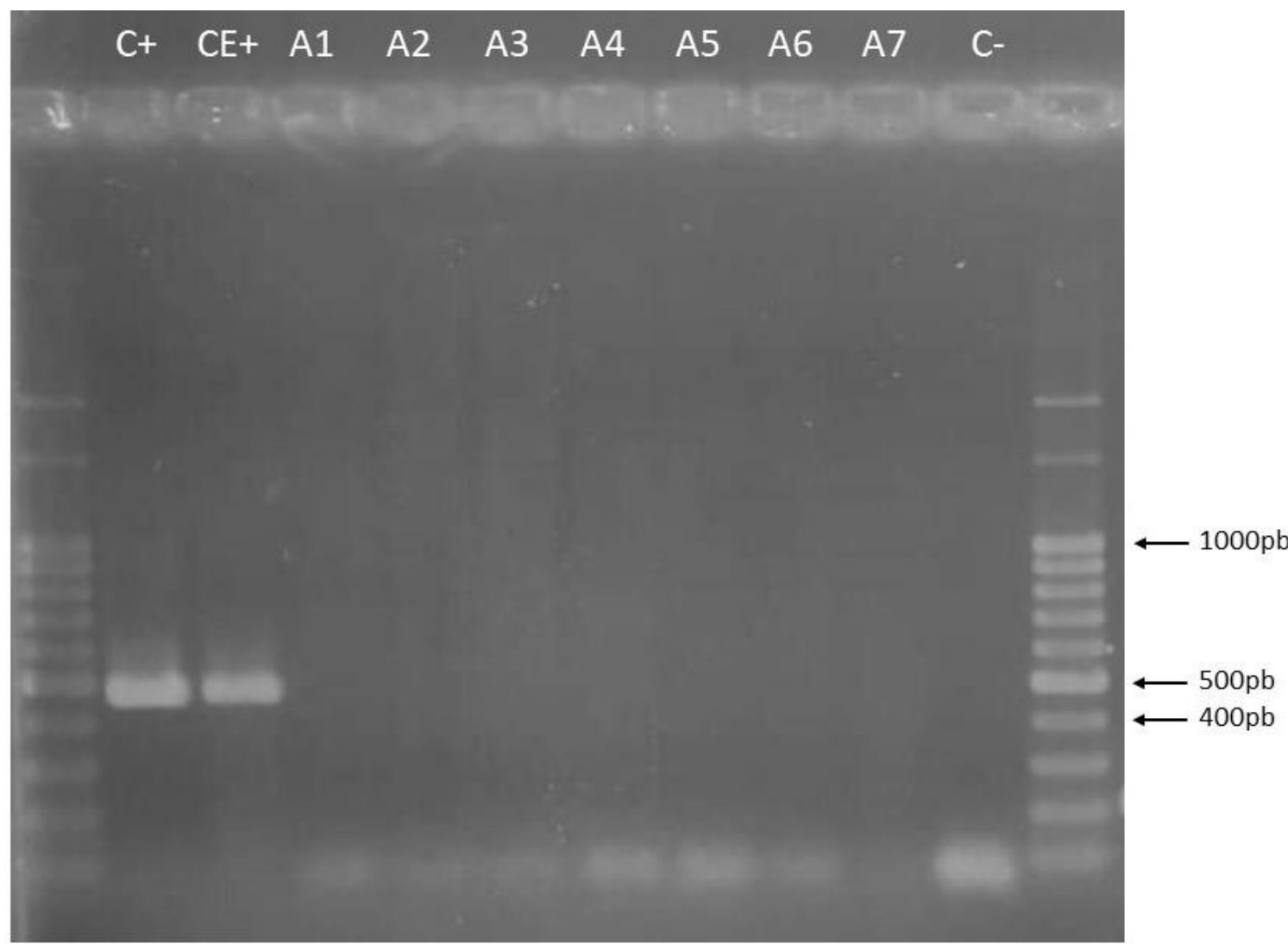

Fonte. Autores.

Figura 4 - 4A- Imunohistoquímica de sarcoide tipo verrucoso apresentado reação positiva para vimentina (V9 1:200 Biocare Medical) [IHQ; obj. 10x]. 4B- Imunohistoquímica negativa para S100P ACI 3010 A, B 1:200 Biocare Medical). [IHQ; obj. 10x].

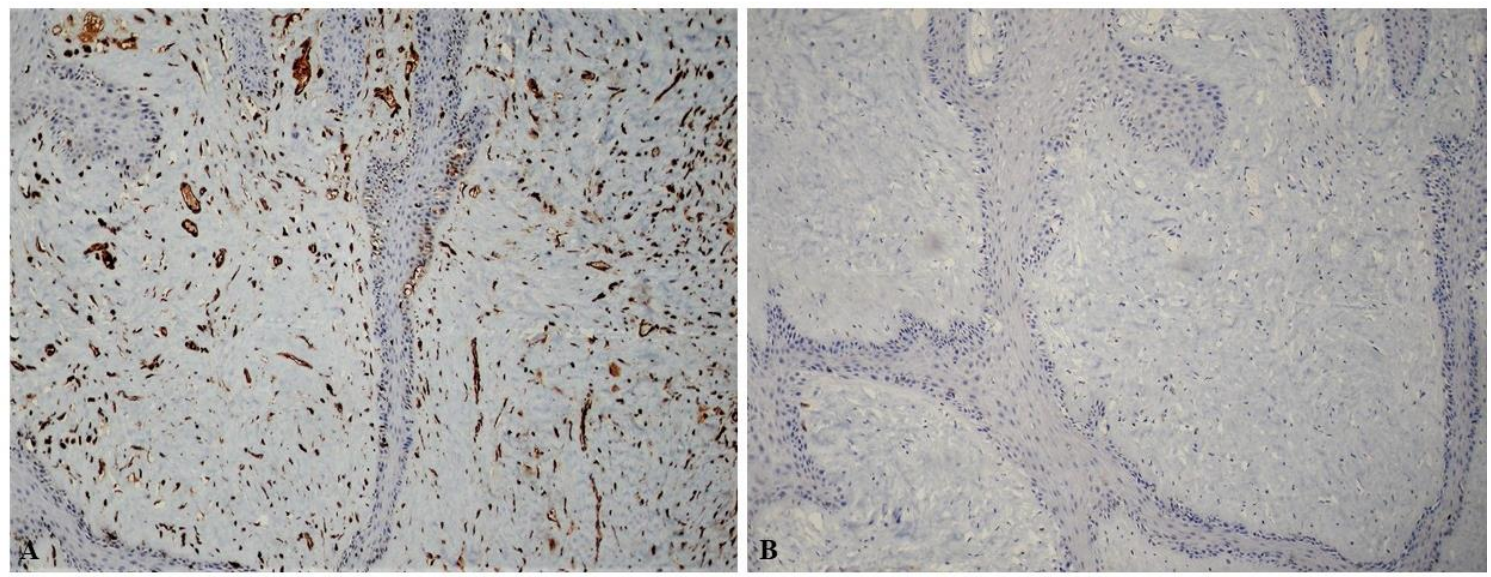

Fonte. Autores. 


\section{Discussão}

O presente estudo revelou que sarcoide equino na Região Sul do Rio Grande do Sul representou mais de $40 \%$ das enfermidades tegumentares desta espécie animal em um período de 20 anos, sendo considerado como a mais importante dentre as doenças de pele dos equinos, do mesmo modo que é mencionado em outros trabalhos de estudos retrospectivos (Ramos et al., 2008; Marcolongo-Pereira et al., 2014; Assis-Brasil et al., 2015; Pinheiro et al., 2015; Bianchi et al., 2016). Percentuais de $32,9 \%$ e 33,5\% de casos de sarcoide foram encontrados entre todas as doenças de pele diagnosticadas em dois estudos em diferentes regiões do Estado (Assi-Brasil et al., 2015; Bianchi et al., 2016). Dentre os tumores cutâneos este percentual chegou a 57,4\% em um período de 11 anos (Silva et al., 2010).

Foi demonstrado que a raça Crioula é a mais frequentemente afetada, sendo encontrados percentuais de 77,5\% dos casos (Brum et al., 2010) e 52\% dos casos (Bianchi et al., 2016) nesta raça em trabalhos desenvolvidos no Rio Grande do Sul. No presente estudo foi encontrado um percentual de 75,9\%, semelhante aos percentuais já descritos. Isso certamente deve-se ao fato de que esta é a raça de equinos mais criada no Estado. Nos Estados Unidos a raça mais frequentemente afetada foi a Quarto de Milha em um estudo retrospectivo de 12 anos (Angelos et al., 1988), embora com um total de materiais de equinos recebidos no Hospital ligeiramente inferior ao da raça Thoroughbred e o maior número de casos na raça Quarto de Milha foi atribuído à maior susceptibilidade genética nesta raça. No presente trabalho o número de materiais de equinos ou biopsias de tumores de equinos da raça Crioula é muito superior às demais raças e aos animais sem raça definida e, portanto, não é possível atribuir a maior frequência de sarcoide nestes animais à fatores genéticos.

O percentual de fêmeas afetadas foi ligeiramente superior ao de machos, demonstrando que o sexo aparentemente não interfere na ocorrência do sarcoide, conforme tem sido observado por outros autores (Brum et al., 2010; Bianchi et al., 2016). No presente trabalho equinos adultos jovens foram os mais afetados com quase metade dos casos, seguidos pelos equinos adultos. Na região central do Estado foi encontrado um percentual de $73 \%$ para equinos de um a cinco anos (Brum et al., 2010). Essas diferenças podem estar relacionadas ao número de equinos avaliados que no presente trabalho foi superior.

No presente trabalho observou-se que o maior número de casos era proveniente dos municípios de Pelotas e Capão do Leão, que são os municípios mais próximos ao Laboratório e por outro lado, municípios com maior número de equinos como Bagé e D. Pedrito (IBGE, 2017) tem um menor percentual na casuística do sarcoide. Uma razão para esse menor número de casos ocorre, provavelmente, porque estes municípios estão localizados a maior distância, o que certamente dificulta a remess a de material para diagnóstico. Estes municípios tradicionalmente têm grandes criações de gado cujo manejo é feito por equinos utilizados para o trabalho, sendo de esperar-se que o número de casos de sarcoide fosse maior devido ao fator de risco pelo contato entre estas espécies. Nesta região existem, também, haras de criação de equinos PSI porem a doença foi observada somente em dois equinos desta raça em todo o período do estudo, demonstrando que o controle sanitário nestas propriedades é eficiente para evitar a disseminação do vírus. Por outro lado, são mencionados outros fatores de risco como a predisposição genética que parece ser importante para o desenvolvimento e gravidade das lesões de sarcoide (Knottenbelt, 2005; Bergvall, 2013). Foi demonstrado, também, que mesmo sem contato com bovinos o risco de um equino saudável adquirir a infecção pelo BPV de outro equino com sarcoide é o mesmo que se tiver contato com bovinos com papilomatose (Bogaert et al., 2008).

Embora a maioria dos relatos mencione a maior prevalência de tumores múltiplos (Brum et al., 2010; Bianchi et al., 2016), no presente trabalho foi observado que $61 \%$ dos diagnósticos foram de sarcoides únicos. Em um estudo no Nordeste os sarcoides únicos representaram 87,2\% dos casos (Pessoa et al., 2014).

Observou-se uma tendência de evolução dos sarcoides tanto únicos como múltiplos entre um e três meses. Esse dado, no entanto, deve ser avaliado com cuidado, uma vez que não estava presente em todos os protocolos. Além disso, outros fatores podem interferir na evolução desses tumores. Em um estudo da evolução da doença em equinos da raça Franches 
Montagnes foi observado que o curso do sarcoide é notoriamente imprevisível e aparentemente independe da localização da lesão, tipo de lesão, idade e fatores ambientais (Berruex et al., 2016).

É mencionado que a recidiva de sarcoide é frequente e pode ocorrer em poucos dias, semanas, meses ou anos (Funiciello \& Roccabianca, 2020), no entanto os autores salientam que essas recidivas podem ser decorrentes da disseminação do tumor durante a cirurgia ou pela incompleta remoção da lesão. A indicação de tratamento cirúrgico somente em casos de tumores pequenos pode ser eficiente para evitar essas recidivas e melhorar o prognóstico de evolução do tumor. Neste trabalho em seis casos recebidos no ano 2021, em que os equinos foram tratados cirurgicamente não houve recidiva em sete meses de acompanhamento dos animais, sugerindo que a retirada completa dos tumores de até 7,5 cm no máximo pode ser eficiente para evitar as recidivas.

No presente trabalho ficou evidenciado que o tipo mais frequente de sarcoide observado na região foi o fibroblástico. Este é, também, o tipo mais frequentemente descrito em diversos relatos sobre a doença (Brum et al., 2010; Gomiero \& Tostes, 2015; Berruex et al., 2016; Bianchi et al., 2016). Com relação aos demais tipos de sarcoide foi observado que o misto foi o segundo mais frequente seguido pelos tipos verrucoso e nodular. Isso foi observado, também, em um trabalho sobre sarcoide realizado na região central do Estado (Brum et al., 2010). Por outro lado, em um estudo no Paraná o segundo tipo mais frequente foi o verrucoso seguido pelo nodular (Gomiero \& Tostes, 2015). Deve-se levar em conta que o número de casos de sarcoide estudado no Paraná foi bem menor (30 casos) do que o do presente relato, o que poderia influenciar nessa diferença de ocorrência.

A maioria dos sarcoide afetou os membros (37,2\%) principalmente os posteriores, o que tem sido observado, também, por outros autores (Pessoa et al., 2014; Aragão et al., 2018). A maioria dos sarcoides múltiplos estava localizada no tronco e a maioria dos tumores únicos foi observada nos membros. Na região central do Estado a maioria dos tumores nos membros era múltipla (Brum et al., 2010). Não há uma explicação para essas variações de localização e multiplicidade dos tumores, sugerindo-se que não há relação direta entre estas duas características do sarcoide.

A imuno-histoquímica dos sete casos, negativa para a proteína S-100 e positiva para vimentina, permitiu diferenciar estes casos de melanoma e tumores da bainha de mielina respectivamente.

Apesar de diversos estudos demonstrarem a presença do vírus relacionada ao desenvolvimento das lesões (Lunardi et al., 2013; Alcântara et al., 2015), alguns autores defendem que a infecção pelo papilomavirus bovino seja não produtiva em equinos, devido ao fato de que o percentual de mRNAs de genes tardios representam menos que 0,3\% dos BPV RNAs transcritos (Wilson et al., 2013). Em um estudo conduzido por Tura et al. (2021) não foi detectado a presença de DNA viral em células da epiderme e da derme adjacentes as células neoplásicas positivas para BPV em sarcoides. Variações quanto ao tipo celular e tecidual com a presença de material genético viral, além da marcante diversidade genética dos BPVs também devem ser consideradas.

Trabalho utilizando outras tecnologias, como a amplificação por RCA (replicação por círculo rolante) e sequenciamento de alto rendimento (HTS) em amostras de papilomas de tetos bovinos permitiram a identificação de 11 BPVs conhecidos e 14 BPVs não descritos na literatura (Sauthier et al. 2021). Estes resultados demonstram que as técnicas convencionais de diagnóstico podem estar subestimando a diversidade genética desta família viral. No presente estudo, foram utilizados os primers degenerados FAP59/64, (amplamente utilizados na literatura científica), porém com limitações inerentes devido a diversidade genética dos BPV. A amplificação por RCA e sequenciamento de nova geração (NGS) nas amostras deste estudo poderiam, eventualmente, revelar a presença de DNA viral de outros tipos de BPV associados aos sarcoides. 


\section{Conclusão}

O registro de 258 casos de sarcoide equino em um período de 20 anos permitiu estabelecer a epidemiologia dessa enfermidade na região Sul do Rio Grande do Sul. É a mais importante neoplasia da pele dos equinos afetando principalmente animais de dois a cinco anos, da raça Crioula, tanto machos como fêmeas, com lesões únicas distribuídas principalmente nos membros e lesões múltiplas, em menor número, observadas principalmente no tronco. A forma fibroblástica é a mais frequente seguida pelas formas mista, verrucosa, oculta e nodular. Concluiu-se também que em tumores de até 7,5cm a excisão cirúrgica completa pode ser eficiente para não haver recidiva em pelo menos sete meses.

\section{Agradecimentos}

Os autores agradecem ao Conselho Nacional de Desenvolvimento Científico e Tecnológico (CNPq) e à Coordenação de Aperfeiçoamento de Pessoal de Nível Superior (CAPES) (código financeiro 001) pelo apoio científico, financeiro e bolsa de estudos. Agradecem, também, ao Prof. Dr. Claudio Wageck Canal do Depto. de Veterinária Preventiva e Patologia, da Universidade Federal do Rio Grande do Sul (UFRGS) pelo controle positivo do DNA do papilomavírus.

\section{Referências}

Abreu, D. B., Cunha, M. E. N., Silva, E. N., Menezes, R. V., Ferreira, M. M., Araújo, A. L. \& Ayres, M. C. C. (2018). Sarcóide recidivante em glande de um equino: Relato de caso. Pubvet, 12(2):1-7.

Alcântara, B. K., Alfieri, A. A., Headley, S. A., Rodrigues, W. B., Otonel, R. A. A., Lunardi, M. \& Alfieri, A. F. (2015). Molecular characterization of bovine Deltapapillomavirus (BPV1, 2, and 13) DNA in equine sarcoids. Pesquisa Veterinária Brasileira, 35(4):431-436.

Angelos, J., Oppenheim, Y., Rebhun, W., Mohammed, H. \& Antczak, D. F. (1988). Evaluation of breed as a risk factor for sarcoid and uveitis in horses. Animal Genetics, 19: 411-425.

Anjos, B. L., Silva, M. S., Diefenbach, A., Brito, M. F., Seppa, G. S. \& Brum, M. C. S. (2010). Sarcoide equino associado ao papilomavírus bovino BR-UEL4. Ciência Rural, 40(6): 1456-1459.

Aragão, A. T. I., Raiter, J., Machado, L. F. S., Oliveira, J. E. B. G., Gneiding, B. \& Lucioli, J. (2018). Dermatopathies in horses in the state of Santa Catarina. Revista Acadêmica Ciência Animal, 16(2):162003.

Assis-Brasil, N. D., Marcolongo-Pereira, C., Stigger, A. L., Fiss, L., Santos, B. L., Coelho, A. C. B., Sallis, E. S. V., Fernandes, C. G. \& Schild, A. L. (2015). Equine dermatopathies in southern Brazil: a study of 710 cases. Ciência Rural, 45(3): 519-524.

Bergvall, K. E. (2013). Sarcoids. Veterinary Clincs Equine. 29. 657-671.

Berruex, F., Gerber, V., Wohlfender, F. D., Burger, D. \& Koch, C. (2016). Clinical course of sarcoids in 61 Franches-Montagnes horses over a 5 to 7 year period. Veterinary Quarterly. 36(4):189-196.

Bianchi, M. V., Boos, G. S., Mello, L. S., Vargas, T. P., Sonne, L., Driemeier, D. \& Pavarini, S. P. (2016). A Retrospective Evaluation of Equine Cutaneous Lesions Diagnosed in Southern Brazil. Acta Scientiae Veterinariae, 44:1388.

Bogaert, L., Martens, A., Poucke, M. V., Ducatelle, R., Cock, H. D., Dewulf, J., Baere, C. D., Peelman, L \& Gasthuys, F. (2008) High prevalence of bovine papillomaviral DNA in the normal skin of equine sarcoid-affected and healthy horses. Veterinary Microbiology, $129:$ 58-68.

Brum, J. S., Souza, T. M. \& Barros, C. S. L. (2010). Aspectos epidemiológicos e distribuição anatômica das diferentes formas clínicas do sarcoide equino no Rio Grande do Sul: 40 casos. Pesquisa Veterinária Brasileira, 30(10):839-843.

Forslund, O., Antonsson, A., Nordin, P., Stenquis, B. \& Hansson, B. G. (1999). A broad range of human papillomavirus types detected with a general PCR method suitable for analysis of cutaneous tumours and normal skin. Journal of General Virology, 80: 2437-2443.

Funiciello, B. \& Roccabianca, P. (2020). Equine Sarcoid. From the Edited Volume Equine Science by Dr. Catrin Rutland and Dr. Albert Rizvanov.

Gaynor, A. M., Zhu, K. W., Dela Cruz, F. N., Jr Affolter, V. K. \& Pesavento, P. A. (2015). Localization of Bovine Papillomavirus Nucleic Acid in Equine Sarcoids. Veterinary pathology, 53(3):567-73.

Gomiero, R. L. S. \& Tostes, R. A. (2015). Clinical, anatomopathological and epidemiologic aspects of equine sarcoid 30 case study. Archives of Veterinary Science, 20(2):64-75.

Instituto Brasileiro de Geografia e Estatística (IBGE). (2017). Censo Agropecuário. Brasília, DF. https://www.ibge.gov.br/estatisticas/economicas/agriculturae-pecuaria.html. 
Research, Society and Development, v. 11, n. 3, e43211326704, 2022

(CC BY 4.0) | ISSN 2525-3409 | DOI: http://dx.doi.org/10.33448/rsd-v11i3.26704

International Committee on Taxonomy of Viruses. Poxviridae (ICTV). (2021) 9th report. EC 52, ICTV. https://talk.ictvonline.org/ictvreports/ictv_9th_report/dsdna-viruses-2011/w/dsdna_viruses/121/papillomaviridae.

Knottenbelt, D. C. (2005). A Suggested Clinical Classification for the Equine Sarcoid. (Ed). Técnicas clínicas na prática equina, 4th. Leahurst. 4: $278-295$.

Knottenbelt, D. C. (2019). The Equine Sarcoid Why Are There so Many Treatment Options? Veterinary Clinics Equine, 35:243-262.

Lunardi, M., Alcântara, B. K., Otonel, R. A. A., Rodrigues, W. B., Alfieri, A. F. \& Alfieri, A. A. (2013). Bovine Papillomavirus Type 13 DNA in Equine Sarcoids. Journal of Clinical Microbiology, 51(7):2167-2171.

Marcolongo-Pereira, C., Estima-Silva, P., Soares, M. P., Sallis, E. V. S., Grecco, F. B., Raffi, M. B., Fernandes, C. G. \& Schild, A. L. (2014). Doenças de equinos na região Sul do Rio Grande do Sul. Pesquisa Veterinária Brasileira, 34(3):205-210.

Pessoa, A. F. A., Pessoa, C. R. M., Neto, E. G. M., Dantas, A. F. M. \& Riet-Correa, F. (2014). Doenças de pele em equídeos no semiárido brasileiro. Pesquisa Veterinária Brasileira, 34(8):743-748.

Pinheiro, M., Pimentel, M. M. L., Vago, P. B., Barrêto Junior, R. A. \& Dias, R. V. da C. (2015). Sarcoide equino: revisão de literatura. Arquivos de ciências veterinárias e zoologia, 18(2):103-107.

Quinn, G. (2003). Skin tumours, in the horse: Clinical presentation and management, p.476-483 (Eds), The VeterinaryRecord/In Practice. 25: 476-483.

Ramos, A., Souza, T. A. B., Norte, D. M., Ferreira, J. L. M. \& Fernandes, C. G. (2008). Tumores em animais de produção: aspectos comparativos. Ciência Rural, 38(1): 148-154.

Sauthier, J. T., Daudt, C., Silva, F. R. C., Alves, C. D. B. T., Mayer, F. Q., Bianchi, R. M., Driemeier, D., Streit, R. S. A., Staats, C. C., Canal, C. W. \& Weber, M. N. (2021). The genetic diversity of "papillomavirome" in bovine teat papilloma lesions. Animal Microbiome, 3: 51.

Semik-Gurgul, E. (2020). Molecular approaches to equine sarcoids. Equine veterinary jornal, 53:221-230.

Silva, M. S., Weiss, M., Brum, M. C. S., Anjos, B. L., Torres, F. D., Weiblen, R. \& Flores, E. F. (2010). Molecular identification of bovine papillomaviruses associated with cutaneous warts in southern Brazil. Journal of Veterinary Diagnostic Investigation, 22:603-606.

Souza, T. M., Brum, J. S., Fighera, R. A., Brass, K. E. \& Barros, C. S. L. (2011). Prevalência dos tumores cutâneos de equinos diagnosticados no Laboratório de Patologia Veterinária da Universidade Federal de Santa Maria, Rio Grande do Sul. Pesquisa Veterinária Brasileira, 31(5):379-382.

Szczerba-Turek, A., Siemionek, J., Ras, A., Bancerz-Kisiel, A., Platt-Samoraj, A., Lipczynska-Ilczuk, K. \& Szweda, W. (2019). Genetic evaluation of bovine papillomavirus types detected in equine sarcoids in Poland. Pol. Journal of Veterinary Science, 22(1): 25-29.

Tura, G., Savini, F., Gallina, L., Ragione, R. M., Durham, A. E., Mazzeschi, M., Lauriola, M., Avallone, G., Sarli, G., Brunetti, B., Muscatello, L. V., Girone, C. \& Bacci, B. (2021). Fibroblast-associated protein-a expression and BPV nucleic acid distribution in equine sarcoids. Veterinary Pathology. XX(X).

Wilson, A. D., Armstrong, E. L. R., Gofton, R. G., Mason, J., De Toit, N. \& Day, M. J. (2013). Characterisation of early and late bovine papillomavirus protein expression in equine sarcoids. Veterinary Microbiology, 23;162(2-4):369-380. 